\title{
ENGLISH TERMS OF TERMINOLOGICAL FIELD LEGAL PROFESSION: MOTIVATION OF CHOICE AND TRANSLATION ${ }^{1}$
}

\author{
Nadezhda A. Kalmazova \\ Saratov State Law Academy, Saratov, Russia \\ Viktoria F. Borisova \\ Saratov State Law Academy, Saratov, Russia \\ Julia A. Kuznetsova \\ Saratov State Law Academy, Saratov, Russia
}

\begin{abstract}
The article deals with the urgent issue of translation of special vocabulary. It has been proved, that effective study of English legal terminology by Russian native speakers is possible when there is profound knowledge of the corresponding piece of worldview shared by the English native speakers and understanding how the cognition of one nation is translated into the worldview of another nation. This understanding is achieved by means of studying concepts named by legal terms. The authors have systematized the difficulties, which appear in the process of English-Russian translation of the terms within the field of legal profession. Etymological, universal, national and professional conceptual layers named by the legal terms: barrister, solicitor, attorney, lawyer, adвoкam, coroner, Personal Injury Law have been characterized, the peculiarities, which motivate representative variants of translation - found out. The appearance of new signs in the structure of concepts, represented by the terms legal research, discovery, legal writing has been detected; the choice of translation techniques applied for these terminological units is explained. The research has revealed the changes in the piece of worldview of the English native speakers connected with the appearance of new concepts named by the terms ediscovery and predictive coding. The choice of translation techniques has been justified.
\end{abstract}

Key words: worldview, linguistic worldview, term, legal term, concept, structure of concept, translation, representative variant.

Citation. Kalmazova N.A., Borisova V.F., Kuznetsova Ju.A. English Terms of Terminological Field Legal Profession: Motivation of Choice and Translation. Vestnik Volgogradskogo gosudarstvennogo universiteta. Seriya 2. Yazykoznanie [Science Journal of Volgograd State University. Linguistics], 2020, vol. 19, no. 3, pp. 8496. (in Russian). DOI: https://doi.org/10.15688/jvolsu2.2020.3.8

\section{АНГЛОЯЗЫЧНЫЕ ТЕРМИНЫ ТЕРМИНОПОЛЯ «ЮРИДИЧЕСКАЯ ПРОФЕССИЯ»: МОТИВАЦИЯ ВЫБОРА ПЕРЕВОДА ${ }^{1}$}

Надежда Александровна Калмазова

Саратовская государственная юридическая академия, г. Саратов, Россия

\section{Виктория Федоровна Борисова}

Саратовская государственная юридическая академия, г. Саратов, Россия

Юлия Александровна Кузнецова

Саратовская государственная юридическая академия, г. Саратов, Россия 
Аннотация. Статья посвящена актуальной проблеме перевода специализированной лексики. Доказано, что эффективное изучение юридической терминологии английского языка носителями русского языка возможно с опорой на знания о соответствующем ей фрагменте картины мира носителей английского языка и понимание механизма трансляции представлений одного народа в языковую картину мира другого народа. Такое понимание достигается посредством изучения концептов, именованных юридическими терминами. Ю.А. Кузнецовой систематизированы трудности, которые возникают при переводе терминов, называющих юридические профессии, с английского на русский язык. Ю.А. Кузнецовой, Н.А. Калмазовой, В.Ф. Борисовой охарактеризованы этимологический, универсальный, национальный и профессиональный слои концептов, которые номинированы терминами barrister, solicitor, attorney, lawyer, aдвокат, coroner, Personal Injury Law, и выявлены признаки, мотивирующие подбор репрезентативного приема перевода. Н.А. Калмазовой зафиксированы новые признаки в структуре концептов, репрезентированных терминами legal research, discovery, legal writing, и обоснован выбор приемов перевода этих терминологических единиц. В.Ф. Борисовой установлены изменения фрагмента картины мира носителей английского языка, связанные с формированием новых концептов, обозначенных терминами ediscovery и predictive coding, и обоснован выбор приемов перевода этих терминологических единиц.

Ключевые слова: картина мира, языковая картина мира, термин, юридический термин, концепт, структура концепта, перевод, репрезентативный вариант.

Цитирование. Калмазова Н. А., Борисова В. Ф., Кузнецова Ю. А. Англоязычные термины терминополя «юридическая профессия»: мотивация выбора перевода // Вестник Волгоградского государственного университета. Серия 2, Языкознание. - 2020. - Т. 19, № 3. - C. 84-96. - DOI: https://doi.org/10.15688/jvolsu2.2020.3.8

\section{Введение}

Сегодня изучение языков не мыслится без обращения к картине мира, отраженной в них. Картина мира связана с концептами, то есть представлениями языкового коллектива об окружающей действительности взаимосвязанными квантами знания, которые хранятся в памяти народа и репрезентированы в языке. Анализ концептов позволяет выявить обобщенное ментальное национальное знание и получить достоверные данные о картине мира того или иного этноса. Результаты такого анализа можно использовать для мотивировки подбора репрезентативного варианта перевода с одного языка на другой, в частности перевода терминов с английского языка на русский язык.

Целью работы является описание признаков концептов, именованных юридическими терминами терминополя «юридическая профессия», установление взаимосвязи признаков концепта и выбора репрезентативного варианта перевода, а также определение соответствующего приема перевода.

\section{Материал и методы исследования}

Исследовать концепты возможно в нескольких направлениях. Как отмечает В.И. Карасик, «в рамках лингвокогнитивного направ- ления выявляются способы языковой объективации переживаемого опыта, в рамках лингвокультурологического направления в поле зрения исследователей оказывается этнокультурная или социально-групповая специфика осмысления такого опыта» [Карасик, 2009, с. 11]. Результаты исследования концептов в рамках первого направления могут быть эффективно использованы при изучении иностранного языка и в процессе его преподавания, поскольку глубокое проникновение в систему языка обучающих и обучаемых продиктовано трудностью восприятия иностранных слов и терминов, а также их перевода без понимания их роли в другой культуре.

Методологически значимым в контексте нашего исследования становится высказывание С.П. Хижняка о том, что «представление концептуального пространства языка, совокупности концептосфер, семантического и семиотического пространства языка в виде единых сущностей позволяет говорить о том, что их фрагменты неизбежно должны взаимодействовать, влиять друг на друга, а также могут находиться в отношениях вариативности. Хорошо изученные в терминоведении процессы терминологизации слов общелитературного языка убеждают в том, что совокупности семиосфер, семантических сфер и концептосфер находятся в постоянном взаимодействии, а сама национальная языковая картина мира 
представлена различными вариантами» [Хижняк, 2016, с. 39]. Эти варианты отражают различия картин мира национальных языков, обусловливая трудности перевода.

Объектом нашего исследования послужили концепты, именованные терминами терминополя «юридическая профессия» в английском (британском и американском вариантах) и русском языках.

Усвоение юридических терминов изучаемого иностранного языка начинается с формирования представления о фрагменте картины мира другой культуры и сравнения его с фрагментом картины мира родной культуры. Проникновение в картину мира означает понимание механизма трансляции когниции (cognition) данного народа в языковую картину мира. Когниция реализуется на разных уровнях: индивидуальном и групповом, личностном и обобщенном. Однако это несущественно, если рассматривать вопрос следующим образом: один представитель национального языкового коллектива обладает групповым, обобщенным понятийным фондом, реализованным в его личностном, индивидуальном понятийном фонде, составляющем основу его картины мира, которая идентична групповой, обобщенной картине мира его народа в сравнении с картиной мира другого народа. Следовательно, различия в картинах мира носителей одного языка минимальны и несущественны при сравнении с картиной мира, существующей у представителей другого народа.

Будучи одним из основных в лингвокультурологии, понятие картины мира связано с изучением лексической системы языка, которая, по словам исследователей, занимает главенствующее положение по сравнению с грамматической системой, являющейся вторичной и менее гибкой [Федорова, 2014, c. 11; Bartmiński, 2012, p. 17; Glaz]. Компоненты картины мира составляют концепты, репрезентированные словами. Следовательно, процесс понимания идеи (концепта), стоящей за термином, связан с ее комплексным пошаговым изучением. Правильное понимание и правильная локализация юридических терминов (в нужном месте общей картины мира) - одна из главных задач преподавания иностранного языка для специальных целей [Sierocka, 2016, p. 226].
Для достижения корректного понимания юридической терминологии студентам необходимы глубокие познания в изучаемой предметной области, поскольку знакомства с определением терминов недостаточно. Как справедливо отмечает С.П. Хижняк, «для формулирования дефиниции из общего набора утверждений отбирается только часть полного концепта» [Хижняк, 2016 с. 121], а для усвоения лексико-фразеологической сочетаемости терминов и приобретения навыков перевода необходимо знать все частотные варианты функционирования терминов в терминосистеме. Всего перечисленного можно достичь посредством анализа концептуальных слоев «этимологического (экстралингвистические факторы формирования концепта, мотивированность именования концепта, ментальная схема концепта, базовая метафора концепта), универсального (квант знаний, универсальный для многих культур), национального (знания, являющиеся продуктом ментальной деятельности нации или народности: ощущения, восприятия, культурные установки, идиологемы и обусловленные ими оценка и эмотивность) и профессионального (знания, являющиеся продуктом ментальной деятельности профессиональной группы)» [Игнаткина, 2005, с. 11].

Лингвокогнитивное изучение концептов проводится посредством сложных экспериментов, как правило, с участием респондентов носителей языка. Тем не менее достаточно полно охарактеризовать концепты позволяет обобщение языкового материала и интерпретация семантики слов и фразеологизмов, представленные в толковых словарях, анализ новых значений и новой сочетаемости единиц, реализуемых в текстах, которые относятся к той или иной области знания. В исследовании при описании концептов, именованных юридическими терминами в рамках терминополя «юридическая профессия», отбирались только те данные, которые зафиксированы в толковых словарях и в юридических текстах, поскольку они позволяют мотивировать подбор репрезентативного варианта перевода.

\section{Результаты и обсуждение}

При изучении юридической терминологии неизбежно осмысление терминов терми- 
нополя «юридическая профессия». Уже при его освоении необходимо обозначать основные фрагменты британской и американской картин мира и сравнивать их с соответствующими фрагментами русской картины мира. Специфика картин мира обнаруживается: 1) в наличии нескольких терминов в английском языке для номинирования одного понятия в русском языке; 2) в наличии уникального термина в английском языке, отсутствующего в русском языке; 3) в несовпадении терминов, репрезентирующих конкретную сферу деятельности в английском и в русском языках; 4) в появлении современных вариантов традиционных терминов, связанном с развитием компьютерных технологий.

1. Несовпадение картин мира обнаруживается в базовых терминах - названиях представителей юридической профессии: barrister, solicitor, attorney, lawyer, адвокат. В разных культурах существуют схожие понятия, однако имеются некоторые различия в составе концептуальных слоев. В этимологическом слое они обусловлены происхождением терминов. В Англии и Уэльсе уже в XV в. существовало строгое разграничение адвокатов, отразившееся в терминах barrister и solicitor и сохранившееся до настоящего времени. Концепт «barrister» сформировался на основании признака, определяющего важнейшую функцию представителя данной юридической профессии: «a legal practitioner admitted to plead at the Bar» (Oxford Dictionary of Law, p. 67). В основе концепта «solicitor» также лежит идея выполнения должностных обязанностей: «from Middle French soliciteur, meaning one who conducts matters on behalf of another» (Oxford Dictionary of Law, p. 432). В этимологическом слое концептов «barrister» и «solicitor» прослеживается их базовое различие, а именно связь барристера с работой в суде, а солиситора с обсуждением юридических вопросов с клиентами. В США взаимозаменимы термины attorney, заимствованный из французского: attorne - «appointed or assigned», и lawyer «modification of the word law originally meaning to lay - something laid down or fixed» (Oxford Dictionary of Law, p. 89). В русском языке концепт «адвокат» сформировался на основании идеи необходимости предоставления юридической помощи населению: адвокат от лат. advocāre - «призывать, приглашать, помогать» (Большая юридическая энциклопедия, с. 13).

В универсальном слое на уровне интегральных и дифференциальных признаков понятий различий не наблюдается: во всех рассматриваемых культурах термины barrister, solicitor, attorney, lawyer и адвокат обозначают лицо, предоставляющее правовую помощь юридическим и физическим лицам.

В национальном слое концептов, именованных терминами barrister, solicitor, attorney, lawyer и адвокат, лежат представления, связанные с особенностями функционирования государственных правовых систем в Великобритании, США, России. В Великобритании принятой культурной установкой является первичное обращение клиента к солиситору, и только в сложных случаях, требующих высшей квалификации и рассмотрения в суде высшей инстанции, солиситор обращается за помощью к барристеру; личное обращение клиента к барристеру невозможно. В США одной из основных культурных установок обращения клиента к услугам атторна / лоера является понимание их узкой специализации. В случае возникновения трудовых споров клиент будет работать с одним адвокатом, а в случае с выплатами по медицинской страховке - с другим. К особенностям относится также локализация работы атторна / лоера (в каждом штате выдается своя лицензия на адвокатскую деятельность). В России адвокат имеет широкую специализацию и уполномочен представлять интересы своего клиента в суде любой инстанции.

В профессиональном слое концептов, именованных терминами barrister, solicitor, attorney, lawyer и адвокат, наблюдаются сходства интегральных признаков понятий (например, получение специального юридического образования, присуждение ученой степени в области юриспруденции, приобретение специальных навыков, выбор практической специализации) и различия дифференциальных признаков: а) система образования (например, эффективная система работы студентов с тьюторами в Великобритании, отработка большого количества практических навыков в системе юридического образования в США, акцент на теоретическую юриспруденцию в России); б) формулировка квалификации, уче- 
ной степени, указанных в документах об образовании ( $L L B$ в Великобритании, Juris Doctor в США, магистр в области юриспруденции в России); в) содержание учебных программ юридических факультетов в вузах разных стран; г) организация процесса получения разрешения на практическую деятельность и характер документов, предоставляющих такое право.

На основании схожих признаков в структуре концептов «barrister», «solicitor», «attorney», «lawyer» и «адвокат» в универсальном и профессиональном слоях делаем вывод о возможности перевода терминов barrister, solicitor, attorney, lawyer на русский язык с использованием приема генерализации посредством термина адвокат в случае, если в тексте оригинала речь идет об общих положениях работы адвоката, или приема транслитерации (барристер, солиситер, атторн) в случае, если в тексте оригинала затрагиваются национально-специфические аспекты деятельности юристов.

2. Специфика картин мира разных социумов проявляется в случаях, когда какое-либо понятие отсутствует в картине мира одного народа, но существует в картине мира другого народа, поэтому при его переносе в другую культуру необходимо точно представлять его локализацию и признаки. Например, в Великобритании имеется должностное лицо, участвующее в производстве по уголовным делам, - coroner (коронер): «an officer of the Crown whose principal function is to investigate deaths suspected of being violent or unnatural. He will do this either by ordering an autopsy or conducting an inquest. The coroner also holds inquests on treasure trove. Coroners are appointed by the Crown from among barristers, solicitors, and qualified medical practitioners of not less than five years' standing» (Oxford Dictionary of Law, p. 93). В его обязанности входит установление причины смерти в тех случаях, когда она не является очевидной. Он не расследует дело, а контролирует следственные действия. В российской и американской следственных системах такая должность отсутствует. В результате анализа концепта, именованного термином coroner, установлено, что все его слои имеют уникальную реализацию. Эксклюзивность этимологического слоя обусловлена тем, что данный институт власти возник еще в 1194 г. с появлением сборщиков налогов и развился до независимого судебного органа: «the role of the coroner has adapted over the eight centuries since the office was formally established in 1194, from being a form of medieval crown tax gatherer to an independent judicial officer charged with the investigation of sudden, violent or unnatural death» (http://www.coronersociety.org.uk); компоненты 'crown' и 'gatherer' слились в сознании народа, сформировав новый концепт. Универсальный слой концепта «coroner» отсутствует, поскольку подобная следственная деятельность не зафиксирована в картинах мира других культур. Национальный слой концепта «coroner» связан с принадлежностью к правовой культуре Великобритании. Основу профессионального слоя данного концепта составляют профессиональные знания, такие как контроль официальным представителем королевского судебно-следственного органа действий при расследовании случаев с неустановленной причиной смерти на предмет определения состава преступления. Термин coroner связан с терминополем «расследование уголовных преступлений» и с соответствующим ему британским фрагментом картины мира. Однако ни один из слоев концепта «coroner» не имеет соответствия в каком-либо фрагменте американской и русской картин мира. Поэтому при переводе данного термина на русский язык необходимо применять такие приемы перевода термина coroner, как переводческий комментарий и транслитерация (представитель судебно-следственной службы Великобритании, расследующий дела с неустановленной причиной смерти на предмет определения состава преступления; коронер).

3. Специфика картин мира проявляется в несовпадении терминов, обозначающих конкретную сферу деятельности в английском и в русском языках. При изучении терминосистемы «юридическая профессия» важно сравнение отраслей права, в которых специализируются и, вероятно, будут практиковать выпускники юридических факультетов. В Великобритании по окончании юридического факультета студент должен выбрать путь барристера или солиситора. Их подготовка и специфика работы имеет существенные различия. 
Переход из одной сферы деятельности в другую практически невозможен, так как требует получения соответствующего образования и прохождения двухгодичной практики. Отрасли права, в которых работают барристеры, представлены 9 терминами; у солиситоров их 26 (http://www.chambersstudent.co.uk). В США адвокат (attorney) может работать в любой из отраслей права по своему выбору, а также имеет возможность переквалифицироваться по своему желанию. Их работа ограничивается рамками одного штата (в каждом штате выдается своя лицензия на практику), а также они имеют узкую специализацию, что манифестируется в многокомпонентном дроблении отраслей права в американской картине мира. Отрасли права, в которых работают адвокаты в США, представлены 119 единицами (http://www.bestlawfirms.usnews.com). В России выбор отрасли права возможен по трем направлениям: гражданское, уголовное, административное. По окончании высшего учебного заведения российские выпускники имеют возможность выбрать любую сферу юриспруденции, независимо от специализации, указанной в приложении к диплому, и работать сразу в нескольких смежных отраслях, например банковское, таможенное и финансовое право.

Итак, идентичных отраслей права, в которых работают адвокаты Великобритании, США и России, мало. Многие отрасли права выделены в самостоятельные в одной стране, но составляют часть более обширной отрасли права - в другой (Entertainment Law, Motion Pictures and Television, Music в Великобритании; Sports, Media and Entertainment в США; спортивное право в России). Более того, существуют уникальные отрасли права, регулирующие такие юридические вопросы, которые возникают только в одной из стран (Capital Markets в Великобритании, Native American Law в США, возмещение вреда в результате совершения противоправных действий в России). Следовательно, фрагменты картин мира, отражающие представления об отрасли специализации адвокатов, не совпадают в британской, американской и российской культурах, что приводит к трудностям перевода ряда терминов. В Великобритании и в США выделяется такая отрасль специализации адвокатов, как Personal Injury Law.
Этимологический слой концепта «personal injury law» основывается на идее о причиненном телесном вреде конкретному лицу (personal injury - личный вред) и применении в соответствии со степенью тяжести вреда определенных юридических норм (law - закон). Универсальный слой данного концепта не выделяется, так как эта отрасль права существует только в англо-американской правовой культуре. Уникальность его национального слоя связана с культурными установками граждан Великобритании и США о необходимости наказания юридического или физического лица, ненамеренно совершившего неосторожные действия, которые мог предвидеть разумный человек: «injury which is caused accidentally by another's failure to use reasonable care» (Oxford Dictionary of Law, p. 329), и получения истцом значительной компенсации ущерба. Профессиональный слой формируется знаниями о всех случаях, квалифицируемых соответственно данному деликту, и о юридических нормах, применяемых в каждом конкретном деле.

В картине мира жителей России существует иное представление о случаях, связанных с причинением личного вреда. Как правило, они подразделяются на административные правонарушения (если был причинен легкий вред здоровью) и уголовные правонарушения (если был причинен серьезный вред). В связи с этим случаи причинения личного вреда рассматриваются в рамках административного или уголовного права, в отличие от ситуации в Великобритании и в США, где данные вопросы регулируются гражданским (деликтным) правом. При переводе термина Personal Injury Law необходимо опираться на существенные признаки концепта «personal injury law» ('телесный вред', 'лицо', 'закон', 'наказание', 'неосторожные действия'): omрасль англо-американского права, в которой регулируются вопросы о причинении физическому лииу телесного вреда по неосторожности. Применение описательного приема перевода мотивировано уникальностью и сложностью концепта, именованного термином Personal Injury Law.

4. Специфика картин мира может состоять в появлении в одном из языков новых терминов. При изучении темы «Юридическая 
профессия Великобритании и США» студенты знакомятся с терминами legal research, discovery и legal writing. Понятия, закрепленные за этими терминами, связаны с терминополем профессиональных юридических навыков, необходимых в практической деятельности английских и американских юристов. В настоящее время определение места концептов, именованных этими терминами, в языковой картине мира затрудняет тот факт, что на legal research, discovery и legal writing влияет развитие компьютерных технологий. Очевидно, что картина мира современного человека постоянно изменяется. Это способствует появлению у терминов новых значений и в целом формированию новых концептов [Ивлева, 2018].

При ознакомлении студентов с терминами legal research, discovery и legal writing необходимо отметить, что они обозначают практические навыки, которые формируются при обучении на юридическом факультете и после его окончания при прохождении практики.

Приведем объяснения рассматриваемых терминов, взятые с сайтов юридических фирм. Они дают представление о фрагменте картины мира, в которой аккумулируются концепты, именованные этими терминами: «Legal research is the process of identifying and retrieving information necessary to support legal decision-making》 (http:// lexisnexis.com); «In law, discovery is the exchange of legal information and known facts of a case» (http://www.isaacsandissaacs.com). В Великобритании эквивалентом термина discovery является термин disclosure: «Legal writing. In many legal settings specialized forms of written communication are required. In many others, writing is the medium in which a lawyer must express their analysis of an issue and seek to persuade others on their clients' behalf. Any legal document must be concise, clear, and conform to the objective standards that have evolved in the legal profession» (https://www.law.cornell.edu/ wex/legal_writing).

На основании представленных объяснений юридических терминов можно утверждать, что существует большой объем работы, выполняемой помощниками юристов или начинающими юристами - trainees, pupils, associates и paralegals. Они выполняют низкоквалифицированную рутинную работу по предварительной подготовке материалов дела, которая, как правило, занимает много времени. Этой работой обычно занимается большой штат юристов любой фирмы. Таким до недавнего времени представлялся фрагмент картины мира, эксплицируемый терминами legal research, discovery и legal writing.

Сегодня многие английские и американские исследователи фиксируют изменения в некоторых сферах юридической деятельности и предполагают, что выполнение рутинной работы будет максимально автоматизировано, что все больше видов деятельности будут разбиваться на выполнение мелких задач, которые будут решаться посредством применения разных технологий и удешевляться: performance of routine tasks will be increasingly automated, and more and more jobs will involve managing legal processes by breaking them down into smaller tasks and applying technological solutions to achieve maximum cost-effectiveness [Susskind, 2013, p. 63-85]. По мнению специалистов, это напрямую связано с тем, что юридические фирмы ощущают растущее давление со стороны клиентов по вопросу предоставления более качественных услуг по более доступной цене. Однако они должны оставаться конкурентными по сравнению с провайдерами юридических услуг, которые работают на основании альтернативных моделей бизне$\mathrm{ca}$, способствующих снижению общей стоимости услуг, которые они предоставляют потребителю. Это дает возможность привлечь таких потребителей, которые из-за высокой стоимости ранее не пользовались определенного рода услугами или пользовались ими частично: «Law firms are facing mounting pressure from clients to deliver more efficient services at lower cost. At the same time, they must compete with legal services providers who operate under alternative business models. These providers can leverage new technologies to create efficiencies and drive down overhead costs, which they generally then pass on to consumers. This enables providers to serve those consumers who, for cost reasons, were previously underserved or unserved by the profession» [Law Firms..., 2015].

В исследованиях Дж. МакГинниса и Р. Пирса, посвященных выявлению роли искусственного интеллекта в работе юристов, описано пять отраслей юридической деятель- 
ности, где искусственный интеллект будет выполнять работу, которую сегодня выполняют юристы: «discovery, legal search, document generation, brief generation, and prediction of case outcomes ... researchers describe five areas in which machine intelligence will provide services or factors of production currently provided by lawyers: discovery, legal search, document generation, brief generation, and prediction of case outcomes» [McGinnis, Pearce, 2014]. На основании представленной информации можно сделать вывод о том, что концепты, обозначенные юридическими терминами legal research, discovery и legal writing, находятся в процессе изменений, обусловленных развитием новых компьютерных технологий.

При определении структуры концептов «legal research», «discovery» и «legal writing» необходимо, во-первых, изучить словарные дефиниции терминов, их номинирующих, вовторых, рассмотреть особенности функционирования этих терминов в текстах, связанных с описанием современной ситуации в сфере предоставления юридических услуг. Материал текстов позволил провести сравнительный анализ традиционного и современного наполнения концептов «legal research», «discovery» и «legal writing» (см. табл. 1-3); традиционное понимание характеризуется на основе признаков, выделенных из словарных толкований, а современное понимание - на основе признаков, отраженных в современных специализированных текстах.

Концепты, обозначенные терминами legal research, discovery и legal writing, приобрели дополнительные характеристики в профессиональном слое. Именно в нем находят отражение экстралингвистические условия использования терминов и именно в нем появляются новые значимые компоненты, которые модифицируют картину мира данной отрасли знания. Некоторые аспекты профессиональной работы юристов стали другими. Это незаметно клиентам - обычным гражданам, так как им открыта лишь внешняя сторона юридической деятельности, связанная с ее результатом. Данный факт свидетельствует о стабильности этимологического, универсального и национального слоев концепта.

Влияние компьютерных технологий на содержание деятельности, обозначенной юридическими терминами legal research, discovery и legal writing, обнаруживается в концептуальной составляющей их значений.

\section{Таблица 1. Концепт «legal research»}

Table 1. Concept «legal research»

\begin{tabular}{|l|l|l|}
\hline \multicolumn{1}{|c|}{ Слой концепта } & \multicolumn{1}{|c|}{ Традиционное понимание } & \multicolumn{1}{c|}{ Современное понимание } \\
\hline Этимологический & search for the law & search for the law \\
\hline Универсальный & $\begin{array}{l}\text { legal practice, statutes, legal theory, primary } \\
\text { law, regulations }\end{array}$ & $\begin{array}{l}\text { legal practice, statutes, legal theory, primary } \\
\text { law, regulations }\end{array}$ \\
\hline Национальный & $\begin{array}{l}\text { common law, precedent, binding law, } \\
\text { paralegal }\end{array}$ & $\begin{array}{l}\text { common law, precedent, binding law, } \\
\text { paralegal }\end{array}$ \\
\hline Профессиональный & legal precedent, brief, trial, legal opinion & $\begin{array}{l}\text { legal precedent, brief, trial, legal opinion, } \\
\text { predictive coding, machine intelligence, } \\
\text { computerized legal search }\end{array}$ \\
\hline
\end{tabular}

\section{Таблица 2. Концепт «discovery»}

\section{Table 2. Concept «discovery»}

\begin{tabular}{|l|l|l|}
\hline \multicolumn{1}{|c|}{ Слой концепта } & \multicolumn{1}{|c|}{ Традиционное понимание } & \multicolumn{1}{c|}{ Современное понимание } \\
\hline Этимологический & $\begin{array}{l}\text { inspection of the documents by the opposing } \\
\text { party }\end{array}$ & $\begin{array}{l}\text { inspection of the documents by the opposing } \\
\text { party }\end{array}$ \\
\hline Универсальный & $\begin{array}{l}\text { party, civil litigation, claim, proceeding, } \\
\text { document review }\end{array}$ & $\begin{array}{l}\text { party, civil litigation, claim, proceeding, } \\
\text { document review }\end{array}$ \\
\hline Национальный & $\begin{array}{l}\text { standard disclosure (British), general / specific } \\
\text { disclosure (British), small claims track (British), } \\
\text { extensive discovery (USA) }\end{array}$ & $\begin{array}{l}\text { standard disclosure (British), general / specific } \\
\text { disclosure (British), small claims track (British), } \\
\text { extensive discovery (USA) }\end{array}$ \\
\hline Профессиональный & $\begin{array}{l}\text { case management conference, notice requesting } \\
\text { inspection, deposition }\end{array}$ & $\begin{array}{l}\text { case management conference, notice requesting } \\
\text { inspection, deposition, predictive coding, } \\
\text { ediscovery }\end{array}$ \\
\hline
\end{tabular}




\section{Таблица 3. Конщепт «legal writing»}

\section{Table 3. Concept «legal writing»}

\begin{tabular}{|l|l|l|}
\hline \multicolumn{1}{|c|}{ Слой концепта } & \multicolumn{1}{|c|}{ Традиционное понимание } & \multicolumn{1}{c|}{ Современное понимание } \\
\hline Этимологический & drafting legal documents & drafting legal documents \\
\hline Универсальный & $\begin{array}{l}\text { specialized forms of written communication, } \\
\text { concise and clear legal documents, conformation } \\
\text { to the objective standards }\end{array}$ & $\begin{array}{l}\text { specialized forms of written communication, } \\
\text { concise and clear legal documents, } \\
\text { conformation to the objective standards }\end{array}$ \\
\hline Национальный & $\begin{array}{l}\text { all legal documents: forms of action, contracts, } \\
\text { pleadings, claims, complaints, briefs, memos etc. }\end{array}$ & $\begin{array}{l}\text { all legal documents: forms of action, contracts, } \\
\text { pleadings, claims, complaints, briefs, memos etc. }\end{array}$ \\
\hline Профессиональный & $\begin{array}{l}\text { analysis of an issue, persuasion of a client or } \\
\text { other parties }\end{array}$ & $\begin{array}{l}\text { analysis of an issue, persuasion of a client or } \\
\text { other parties, computer generated forms, } \\
\text { automatic creation of the docum ents, } \\
\text { document generator, improvem ent of } \\
\text { formuliac input, word processing, speech-to- } \\
\text { text programs }\end{array}$ \\
\hline
\end{tabular}

Картина мира расширяется, возникает новая правовая дисциплина - predictive analysis (аналитическое прогнозирование). Суть прогностической деятельности в юриспруденции сводится к сбору с использованием компьютерных технологий важных юридических данных (например, при сравнении фактов по делу или при подборе прецедента посредством машинного анализа повторов фактов разных дел), в результате которого появляется возможность быстро и точно прогнозировать исход того или иного дела, которое ведет адвокат. Аналитическое прогнозирование остается трендом юриспруденции последнего десятилетия, формируется его терминологический аппарат, возникают новые концепты.

Одним из главных инструментов аналитического прогнозирования при проведении процедуры электронного раскрытия доказательств (ediscovery) с использованием компьютерных технологий является кодирование с предсказанием (predictive coding). С его помощью стало возможным внесение фундаментальных изменений в процедуру электронного раскрытия доказательств. В процессе кодирования с предсказанием юристы используют готовые формы большого количества документов. Специальные компьютерные алгоритмы способны предсказывать релевантность документа. Хотя при применении этого метода возможен пропуск нескольких документов, степень точности обработки информации выше по сравнению с результатом, который получен при выполнении такой работы человеком. Когда юристы работают с документами, на них влияет усталость, монотон- ность и однообразие деятельности, чуждые компьютеру. Эффективность кодирования с предсказанием доказана благодаря его применению в делах, получивших широкую огласку.

Таким образом, картины мира у носителей британской и американской культур меняются, объем концептов, обозначенных терминами legal research, discovery, legal writing, имеющими связь с компьютерными терминологиями, расширяется. Терминосистема пополняется новыми терминами.

На начальном этапе знакомства студентов с терминами legal research, discovery, legal writing необходимо использовать аутентичный иллюстративный материал. После его освоения можно проводить сравнительный анализ терминов английского и русского языков с целью определить репрезентативный вариант перевода. Это означает, что нужно транслировать часть картины мира юридической терминологии английского языка в российскую картину мира. Термины legal research, discovery, legal writing и понятия, которые они означают, культуроспецифичны. Их дословный перевод не имеет смысла, так как не отражает ни одного концептуального слоя. Например, словарный перевод термина research - исследование - связан с концептом «научное исследование», отражающим представления об узкоспециальной и теоретической деятельности, и не актуализирует признаков, характеризующих практическую юридическую деятельность. Перевод термина discovery - omкрытте - связан в российском сознании с историко-географической сферой. Перевод 
слова writing как письмо актуализирует идеи о создании письменного текста или изучении грамматических правил письма.

Для репрезентативного перевода этих терминов необходимо знать содержание практической деятельности, которую выполняют российские юристы. Когда российский юрист начинает работать по определенному делу, он обращается к кодексам и судебной практике. Хотя в российской системе прецеденты не являются главным источником права, в отличие от англо-американской системы, российские и англо-американские юристы, как их британские и американские коллеги, прорабатывают все документы, имеющие отношение к расследуемому делу. Документы не исследуют, а изучают. Такова лексическая сочетаемость слова документ в русском языке. Далее в переводе следует отразить компоненты разных концептуальных слоев: 'search for the law' (этимологический слой), 'common law', 'precedent' (национальный слой); 'statutes', 'regulations' (универсальный слой). Таким образом, естественным репрезентативным переводом термина legal research следует считать описательный перевод - изучение прецеедентов, законов и документов по фактам данного дела.

В случае с терминами discovery и legal writing репрезентативный перевод должен основываться на словосочетаниях, обозначающих схожие процедуры в российской системе. Они отражают этимологический слой концептов: discovery «inspection of the documents by the opposing party»-исследование доказательств (соответственно, ediscovery электронное исследование доказательств); legal writing «drafting legal documents» - составление юридических документов.

\section{Заключение}

Проведенное исследование дало следующие результаты.

1. Выявлены схожие признаки концептов «barrister», «solicitor», «attorney», «lawyer», «адвокат» в универсальном и профессиональных слоях, что позволило мотивировать перевод терминов barrister, solicitor, attorney, lawyer с использованием приема генерали- зации посредством термина адвокат, если информация текста оригинала не касается исторических или культуроспецифичных аспектов.

2. Ни один из слоев концепта «coroner» не имеет соответствия в каком-либо фрагменте русской картины мира. Для его понимания необходимы пояснения, что предполагает использование таких приемов перевода термина coroner, как переводческий комментарий и транслитерация (представитель судебноследственной службы Великобритании, расследующий дела с неустановленной причиной смерти на предмет определения состава преступления; коронер).

3. При переводе термина Personal Injury $L a w$ необходимо опираться на выявленные в этимологическом и национальном слоях признаки концепта «personal injury law» и использовать их как смысловые компоненты, применяя описательный прием перевода (omрасль англо-американского права, в которой регулируются вопросы о причинении физическому лииу телесного вреда по неосторожности).

4. Трансформации, зафиксированные в профессиональных слоях концептов, обозначенных терминами legal research (изучение преиедентов, законов и документов по фактам данного дела), discovery (исследование доказательств), legal writing (составление юридических документов), мотивируют их перевод. Изменения фрагмента картины мира, отражающего представления о «юридической профессии», привели к появлению новых концептов, именованных терминами ediscovery и predictive coding. Следовательно, можно сделать вывод о гибкости данного слоя концептов и его способности к аккумуляции новых признаков.

Недавние преобразования в картине мира носителей британской и американской культур, отражающей представления о юридической профессии, связаны с появлением терминов ediscovery (электронное исследование доказательств) и predictive coding (кодирование с предсказанием), которые сегодня заимствуются русским языком. Данный факт свидетельствует о естественной взаимосвязи общественной деятельности и языковых процессов. 
Пополнение терминосистемы юриспруденции обусловливает необходимость осмысления новых единиц с точки зрения подбора репрезентативных вариантов перевода. Этому процессу способствует проведение анализа концептуальных слоев терминов. Вариант перевода, который включает максимальное количество исходных концептуальных признаков и при этом отвечает требованию благозвучности, признается репрезентативным.

\section{ПРИМЕЧАНИЕ}

${ }^{1}$ Исследование выполнено при финансовой поддержке РФФИ в рамках научного проекта № 18-29-16111 «Трансформация правового регулирования отношений, связанных с применением цифровых технологий в судебной системе и в системе исполнения судебных актов».

The reported study was funded by RFBR, research project no. 18-29-16111 "Transformation of Legal Regulation of Relations, Connected with Application of Digital Technologies in Legal System and within the System of Enforcement of Court Rulings".

\section{СПИСОК ЛИТЕРАТУРЫ}

Ивлева А. Ю., 2018. Проблема оценки качества перевода: подходы к решению // Вестник Волгоградского государственного университета. Серия 2, Языкознание. Т. 17, № 1. С. 98-106. DOI: https://doi.org/10.15688/jvolsu2.2018.1.10.

Игнаткина А. Л., 2005. Специфика репрезентации концепта public relations фразеологическими средствами американского и британского вариантов английского языка : автореф. дис. ... канд. филол. наук. Саратов. 25 с.

Карасик В. И., 2009. Концепт как единица лингвокультурного кода // Известия Волгоградского государственного педагогического университета. № 10 (44). С. 4-11.

Федорова О. В., 2014. Психолингвистика vs. Когнитивная лингвистика на карте современной науки // Социо- и психолингвистические исследования. Вып. 2. С. 7-20.

Хижняк С. П., 2016. Когнитивная проблематика в общей теории термина. Саратов : Наука. 172 с.

Bartmiński J., 2012. Aspects of Cognitive Ethnolinguistics. L. ; Oakville : CT : Equinox. $256 \mathrm{p}$.

Glaz A. Promoting Dialogue: Polish Cultural Linguistics and Western-Style Cultural Linguistics. URL: http://www.academia.edu/2700548 (date of access: 01.03.2019).

Law Firms in Transition Survey, 2015. Altman Weil, Inc. URL: http://www.altmanweil.com/ dir_docs/resource/1c789ef2-5cff-463a-863a2248d23882a7_document.pdf(date of access: 22.02.2019).

McGinnis J.O., Pearce R.G., 2014. The Great Disruption: How Machine Intelligence Will Transform the Role of Lawyers in the Delivery of Legal Services // Fordman Law Review. Vol. 82, iss. 6. P. 30413066.

Sierocka H., 2016. Action Research in Designing and Implementing Courses of English for Legal Purposes // Studies in Logic, Grammar and Rhetoric. Vol. 45, № 58. P. 225-251.

Susskind R., 2013. Tomorrow's Lawyers: An Introduction to Your Future. L. : Oxford University Press. 288 p.

\section{ИСТОЧНИКИ}

Chambers Student. The Student's Guide to the Legal Profession. URL: http:/www.chambersstudent. co.uk (date of access: 17.01.2019).

Cornell Legal Information Institute. URL: https:// www.law.cornell.edu/wex/legal_writing (date of access: 22.01.2019).

Isaacs and Isaacs. Personal Injury Attorneys. URL: http://www.isaacsandissaacs.com (date of access: 19.03.2019).

LexisNexis. URL: http://lexisnexis.com (date of access: 19.03.2019).

The Coroner's Society of England and Wales. URL: http://www.coronersociety.org.uk.

US News. Law Firms. URL: http:// www.bestlawfirms.usnews.com (date of access: 03.02.2019).

\section{СЛОВАРИ}

Большая юридическая эничиклопедия - Большая юридическая энциклопедия / В. В. Аванесян [и др.]. М. : Эксмо, 2010. 656 с.

Oxford Dictionary of Law-Oxford Dictionary of Law / ed. by E. A. Martin. Oxford : Oxford University Press, 2003. 551 p.

\section{REFERENCES}

Ivleva A.U., 2018. Problema otsenki kachestva perevoda: podhody k resheniyu [The Problem of Translation Quality Assessment: Approaches 
to Solution]. Vestnik Volgogradskogo gosudarstvennogo universiteta. Seriya 2, Yazykoznanie [Science Journal of VolSU. Linguistics], vol. 17, no. 1, pp 98-106. DOI: https:/ /doi.org/10.15688/jvolsu2.2018.1.10.

Ignatkina A.L., 2005. Spetsifika reprezentatsii kontsepta public relations frazeologicheskimi sredstvami amerikanskogo i britanskogo variantov angliyskogo yazyka: avtoref. dis. ... kand. filol. nauk [Features of Representation of the Concept Public Relations in Phraseological Units of American and British Variants of the English Language. Cand. philol. sci. abs. diss.]. Saratov. 25 p.

Karasik V.I., 2009. Kontsept kak edinitsa lingvokulturnogo koda [The Concept as a Unit of Linguistic Cultural Code]. Izvestiya Volgogradskogo gosudarstvennogo pedagogicheskogo universiteta [Izvestia of the Volgograd State Pedagogical University], no. 10 (44), pp. 4-11.

Fyodorova O.V., 2014. Psikholingvistika vs. Kognitivnaya lingvistika na karte sovremennoy nauki [Psycholinguistics vs. Cognitive Linguistics on the Map of Modern Cognitive Science]. Sotsio- $i$ psikholingvisticheskie issledovaniya [Socio- and Psycholinguistic Studies], iss. 2, pp 7-20.

Khizhnyak S.P., 2016. Kognitivnaya problematika $v$ obshchey teorii termina [Cognitive Aspects of the Term]. Saratov, Nauka Publ. 172 p.

Bartmiński J., 2012. Aspects of Cognitive Ethnolinguistics. London, Oakville, CT, Equinox. $256 \mathrm{p}$.

Glaz A., Promoting Dialogue: Polish Cultural Linguistics and Western-Style Cultural Linguistics. URL: http://www.academia.edu/ 2700548 (accessed March 1, 2019).

Weil A., 2015. LawFirms in Transition Survey. URL: http:/ /www.altmanweil.com/dir_docs/resource/1c789ef2- 5cff-463a-863a-2248d23882a7_document.pdf. (accessed February 22, 2019).

McGinnis J.O., Pearce R.G., 2014. The Great Disruption: How Machine Intelligence Will Transform the Role of Lawyers in the Delivery of Legal Services. Fordman Law Review, vol. 82, iss. 6, pp. 30413066.

Sierocka H., 2016. Action Research in Designing and Implementing Courses of English for Legal Purposes. Studies in Logic, Grammar and Rhetoric, vol. 45, no. 58, pp. 225-251.

Susskind R., 2013. Tomorrow's Lawyers: An Introduction to Your Future. London, Oxford University Press. 288 p.

\section{SOURCES}

Chambers Student. The Student's Guide to the Legal Profession. URL: http://www.chambersstudent.co.uk (accessed January 17, 2019).

Cornell Legal Information Institute. URL: https:// www.law.cornell.edu/wex/legal_writing (accessed January 22, 2019).

Isaacs and Isaacs. Personal Injury Attorneys. URL: http://www.isaacsandissaacs.com (accessed March 19, 2019).

LexisNexis. URL: http://lexisnexis.com (accessed March 19, 2019).

The Coroner's Society of England and Wales. URL: http://www.coronersociety.org.uk.

US News. Law Firms. URL: http://www.bestlawfirms. usnews.com (accessed February 3, 2019).

\section{DICTIONARIES}

Avanesyan V.V. et al. Bolshaya yuridicheskaya entsiklopediya [Large Legal Encyclopaedia]. Moscow, Eksmo Publ., 2010. 656 p.

Martin E.A., ed. Oxford Dictionary of Law. Oxford, Oxford University Press, 2003. 551 p.

\section{Information About the Authors}

Nadezhda A. Kalmazova, Candidate of Sciences (Philology), Associate Professor, Department of the English Language, Saratov State Law Academy, Volskaya St., 1, 410056 Saratov, Russia, kalmazovana@gmail.com, https://orcid.org/0000-0002-5406-0581

Viktoria F. Borisova, Candidate of Sciences (Jurisprudence), Associate Professor, Department of Civil Procedure, Saratov State Law Academy, Volskaya St., 1, 410056 Saratov, Russia, vfb2709@yandex.ru, https://orcid.org/0000-0002-7004-598X

Julia A. Kuznetsova, Candidate of Sciences (Philology), Associate Professor, Department of the English Language, Saratov State Law Academy, Volskaya St., 1, 410056 Saratov, Russia, kuznetsova.julia@mail.ru, https://orcid.org/0000-0001-8851-242X 


\section{Информация об авторах}

Надежда Александровна Калмазова, кандидат филологических наук, доцент кафедры английского языка, Саратовская государственная юридическая академия, ул. Вольская, 1, 410056 г. Саратов, Россия, kalmazovana@gmail.com, https://orcid.org/0000-0002-5406-0581

Виктория Федоровна Борисова, кандидат юридических наук, доцент кафедры гражданского процесса, Саратовская государственная юридическая академия, ул. Вольская, 1, 410056 г. Саратов, Россия, vfb2709@yandex.ru, https://orcid.org/0000-0002-7004-598X

Юлия Александровна Кузнецова, кандидат филологических наук, доцент кафедры английского языка, Саратовская государственная юридическая академия, ул. Вольская, 1, 410056 г. Саратов, Россия, kuznetsova.julia@mail.ru, https://orcid.org/0000-0001-8851-242X 